\title{
Inovasi dan human capital
}

Izzatul Falakhiya - Fakultas Bisnis dan Ekonomika, Universitas Surabaya

\section{Pendahuluan}

Inovasi adalah proses sosial budaya yang kompleks yang melibatkan beragam sumber pengetahuan yang dapat meningkatkan dan mempertahankan keunggulan kompetitif perusahaan dan organisasi, dengan demikian sifat inovasi dapat berkembang untuk proyek ekonomi (Edwards-Schachter, 2018).

Secara keseluruhan interpretasi yang paling diterima tentang sifat inovasi berkaitan dengan gagasan pembaruan melalui generasi dan implementasi ide yang sukses diwujudkan menjadi produk dan layanan yang lebih nyata yaitu penemuan teknologi dan non-teknologi (EdwardsSchachter, 2018). Bagi organisasi bisnis, inovasi bisa dijelaskan sebagai produk baru yang menggunakan teknologi untuk mengeksplorasi atau menciptakan peluang (Mthanti \& Ojah, 2017).

Konsep inovasi telah mendapatkan popularitas dalam beberapa tahun terakhir seperti melalui pembentukan agensi desain, penciptaan pusat-pusat inovasi dalam bisnis, dan pengembangan pendidikan program di fokuskan pada proses inovasi (Garney, et al., 2019). Inovasi terbuka memberikan paradigma baru untuk mempertahankan keunggulan kompetitif perusahaan yang dapat membuka peluang bagi pengetahuan eksternal dan juga memiliki risiko substansial berupa apropriasi dan oportunisme (Brockman, Khurana, \& Zhong, 2018).

Kemampuan perusahaan dalam mengadopsi teknologi untuk mengembangkan inovasi tidak terlepas dari peranan sumber daya manusia, misalnya dengan modal struktural dan relasional (Kianto, Sáenz, \& Aramburu, 2017). Sumber daya manusia dapat memberikan dampak positif dan signifikan terhadap adopsi teknologi dan berpengaruh terhadap kinerja sebuah inovasi (Danquah \& Amankwah-Amoah, 2017). 


\section{Literature Review}

Orientasi kewirausahaan (EO) diperkenalkan pertama kali sebagai suatu konsep di tingkat perusahaan dan para ahli telah meneliti entrepreneurial orientation secara eksklusif (Wincent, Thorgren, \& Anokhin, 2014). EO (Entrepreneurial Orientation) telah berkembang sebagai sebuah pengukuran tentang tingkat kewirausahaan yang telah diterima secara luas baik sebagai variable latent yang terbagi menjadi tiga factor yaitu proaktif, inovasi, dan pengambilan risiko maupun sebagai sebuah variable laten yang diukur menggunakan beberapa item (Rezaei, Ortt, \& Scholten, 2013). Entrepreneurial Orientation ada sebagai variabel kontinu atau satu set variabel yang mewakili satu atau lebih dimensi dimana perusahaan dapat dibingkai (Rodrigo-Alarcón, García-Villaverde, Ruiz-Ortega, \& ParraRequena, 2018).

Entrepreneurial Orientation merupakan sikap strategis dari suatu organisasi terutama berkaitan pada kebijakan-kebjakan dan praktik dasar untuk mengembangkan tindakan kewirausahaan dalam menciptakan keunggulan kompetitif (PráMartens, Machado, Martens, Silva, \& Freitas, 2018). Entrepeneurial Orientation (EO) adalah penentu penting yang menjelaskan keputusan pembiayaan eksternal pemula dan menunjukkan bagaimana hubungan ini dimoderasi oleh risiko tingkat industri dan oleh tahap pengembangan pemula (Vaznyte \& Andries, 2019). EO dipercaya memiliki dampak positif dan kuat terhadap pertumbuhan ekonomi yang telah menyatu pada literatur kewirausahaan (Mthanti \& Ojah, 2017). Orientasi Kewirausahaan (EO) secara luas diakui sebagai prediktor kuat kinerja didalam perusahaan (Pittino, Visintin, \& Lauto, 2017).

Kinerja perusahaan adalah studi yang dapat dikaji dengan ukuran berbasis pasar atau ukuran berbasis akuntansi yang dapat melalui laba persaham, ROA (Return On Asset), ukuran laba, juga ROI (Return On Investment) (Fuzi, Halim, \& Julizaerma, 2016). Tiga aspek kinerja perusahaan yang harus dipelajari adalah : nilai pasar perusahaan, kinerja keuangan, dan inovasi pengeluaran (Zhao, Teng, \& Wu, 2018). Kinerja perusahaan di moderasi oleh keanek aragaman produk (Altaf \& Shah, 2015).

Kinerja perusahaan adalah indikator kapasitas perusahaan untuk mencapai tujuan dan kinerjanya termasuk tindakan finansial yang meliputi faktor ekonomi dan tindakan nonfinansial yang meliputi indikator keberhasilan seperti pangsa pasar, kualitas, kepuasan, dan efektivitas pasar (Zehir, Gurol, Karaboga, \& Kole, 2016). Kinerja perusahaan memiliki beberapa faktor lain yang juga dapat mempengaruhi kinerja perusahaan yang ditambahkan ke 
model sebagai variabel kontrol, seperti Asset to Liability Ratio (ALR), Firm Age (AGE), dan Total Assets (SIZE) (Zhang, Yang, Qiu, Bao, \& Li, 2018).

Kinerja perusahaan juga diartikan ke dalam suatu hal kinerja keuangan yang beberapa langkah-langkah efisiensi keuangannya terdiri dari laba atas ekuitas dan juga laba atas investasi (Rahman \& Ramli, 2014). Kinerja perusahaan dibatasi oleh faktor internal seperti sumber daya dan pilihan strategis, dan faktor eksternal seperti daya dukung lingkungan atau persaingan (Eniola \& Entebang, 2015).Kinerja perusahaan didasarkan pada efisiensi ekonomi yang terdiri dari efisiensi teknis dan alokasi (Floros, Voulgaris, \& Lemonakisa, 2014).

\section{Preposisi I: Innovasi mempengaruhi kinerja perusahaan}

Dapat dikatakan bahwa setiap komponen EO memiliki dampak pada kinerja perusahaan dan menemukan korelasi substansial antara kegiatan pengambilan risiko, proaktif, dan inovasi. Dalam beberapa konteks pengambilan risiko dapat meningkatkan kinerja perusahaan dan meningkatkan prospek masa depan perusahaan (Kurtulmuş \& Warner, 2015). Dengan pengembangan literatur manajemen strategis, konsep baru EO muncul dengan mendefinisikan EO pada tingkat perusahaan adalah merupakan cerminan dari orientasi strategis suatu kinerja perusahaan dengan mempengaruhi hal-hal yang mengarah kepada entri terbaru seperti praktik, proses, dan pengambilan keputusan (Zehir, Can, \& Karaboga, 2015).

Temuan empiris dari penelitian lain menunjukkan bahwa EO secara positif terkait dengan kinerja perusahaan secara bersamaan dan berkelanjutan, dan hubungan positif semacam itu sangat kuat saat kepemilikan keluarga dikombinasi dengan kontrol keluarga dan manajemen yang aktif, sementara dalam tata kelola keluarga pasif, hubungannya menjadi tidak signifikan (Lee \& Chu, 2017). Dalam data analisis lain mengatakan bahwa kinerja inovasi dan strategi diferensiasijuga dapat memediasi pengaruh Entrepreneurial Orientation terhadap kinerja perusahaan dalam variabel lain yaitu internal dan eksternal (Zehir, Can, \& Karaboga, 2015).

Dalam sebuah penelitian lain juga menunjukkan bahwa EO dapat membantu perusahaan berhasil mencapai kinerja yang diharapkan dan bahwa perusahaan dapat mengandalkan MC untuk mengelola turbulensi lingkungan (Pratono \& Mahmood, Entrepreneurial orientation and firm performance: How can micro, small and medium-sized enterprises survive environmental turbulence?, 2015). 


\section{Preposisi II: sumberdaya manusia mempengaruhi strategi perusahaan dalam mengembangkan inovasi}

Sumber daya manusia dapat didefinisikan sebagai pengetahuan, atribut sosial dan kepribadian, pengetahuan, termasuk kreativitas yang terkandung didalam kemampuan yang digunakan untuk melakukan kinerja manusia agar menghasilkan nilai ekonomi (Ruíz, Gutiérrez, Martínez-Caro, \& Cegarra-Navarro, 2017). Sumber daya manusia berketerampilan tinggi atau pada tingkat abstrakisme merupakan dimensi penting dari proses inovasi di tingkat perusahaan dan pada kinerja inovasi produknya (Fonseca, Faria, \& Lima, 2019). Sumber daya manusia yang berkualitas tentunya juga membutuhkan tingkat autonomi yang dalam mengantisipasi perubahan teknologi informasi (Pratono, Ratih, \& Arshad, 2018).

Sumber daya manusia diyakini sebagai sumber utama pengetahuan dan keterampilan dalam proses inovasi, teori pertumbuhan endogen mengambil modal manusia sebagai salah satu input terpenting dalam inovasi dari tingkat makro (Koroglu \& Eceral, 2015). Kualitas sumber daya manusia bisa ditunjukan dengan kemampuan R\&D dalam memanfaatkan sumber daya dari rekan kerja (Pratono, Darmasetiawan, Yudiarso, \& Gyo, 2019). Pengunaan sumber daya manusia terkait pelatihan tugas dan partisipasi karyawan dapat meningkatkan inovasi perusahaan dalam hal keberhasilan komersial pengembangan produk baru dan persentase pendapatan perusahaan dari produk yang baru dikembangkan (Li Ma, Zhai, Zhong, \& Zhang, 2019).

Sumber daya manusia dianggap dapat mempengaruhi kegiatan inovasi yang mengarah pada keuntungan monopolistik yang lebih tinggi dan tumbuh secara endogen dengan pertumbuhan laba dan produksi pesaing monopolistik (Thompson, 2018). Sumber daya manusia bermanfaat dalam kerangka modal intelektual dengan pengembangan sistem indikator dengan tujuan memungkinkan gambaran yang jelas tentang hubungan antara sumber daya manusia dan inovasi dalam perusahaan (Mariz-Perez, Teijeiro-Alvarez, \& Garcìa-Alvarez, 2012). Sumber daya manusia dapat membuka pintu untuk menangkap peluang dan keunggulan kompetititif terhadapa inovasi melalui teori modal intelektual (IC) (Liu, 2017). 


\section{Penutup}

Artikel ini mencooba membangun argument tentang peranan sumber daya manusia dalam mengembangkan inovasi. Tulisan ini menyajikan dua preposisi yang dibangun dari kajian literature mengenai konsep inovasi dalam konteks orientasi kewirausahaan, serta pengelolaan sumber daya manusia. Tentunya, kajian ini masih membutuhkan uji empiris untuk membuktikan preposisi yang telah dibangun.

\section{Bibliography}

Altaf, N., \& Shah, F. (2015). Internationalization and firm performance of Indian firms: Does product diversity matter? Pacific Science Review B: Humanities and Social Sciences, 1(2), 76-84.

Brockman, P., Khurana, I., \& Zhong, R. (2018). Societal trust and open innovation. Research Policy, 47(10), 2048-2065.

Danquah, M., \& Amankwah-Amoah, J. (2017). Assessing the relationships between human capital, innovation and technology adoption: Evidence from sub-Saharan Africa. Technological Forecasting and Social Change, 122, 24-33.

Edwards-Schachter, M. (2018). The nature and variety of innovation. International Journal of Innovation Studies, 2(2), 65-79.

Eniola, A., \& Entebang, H. (2015). SME Firm Performance-Financial Innovation and Challenges. Procedia - Social and Behavioral Sciences, 195, 334-342.

Floros, C., Voulgaris, Z., \& Lemonakisa, C. (2014). Regional Firm Performance: The Case of Greece. Procedia Economics and Finance, 14, 210-219.

Fonseca, T., Faria, P. d., \& Lima, F. (2019). Human capital and innovation: the importance of the optimal organizational task structure. Research Policy, 48(3), 616-627.

Fuzi, S., Halim, S., \& Julizaerma, M. (2016). Board Independence and Firm Performance. Procedia Economics and Finance, 37, 460-465.

Garney, W., Wilson, K., Nelon, J., Hays, C., Garcia, K., Muraleetharan, D., et al. (2019). Understanding innovation in health program planning and development. Evaluation and Program Planning, 73, 226-231.

Kianto, A., Sáenz, J., \& Aramburu, N. (2017). Knowledge-based human resource management practices, intellectual capital and innovation. Journal of Business Research, 81, 11-20.

Koroglu, B. A., \& Eceral, T. O. (2015). Human Capital and Innovation Capacity of Firms in Defense and Aviation Industry in Ankara. Procedia - Social and Behavioral Sciences , 195, 1583-1592. 
Kurtulmuş, B., \& Warner, B. (2015). Entrepreneurial Orientation and Perceived Financial Performance. Does Environment Always Moderate EO Performance Relation. Procedia Social and Behavioral Sciences, 207, 739-748.

Lee, T., \& Chu, W. (2017). The relationship between entrepreneurial orientation and firm performance: Influence of family governance. Journal of Family Business Strategy, 8(4), 213223.

Li Ma, Zhai, X., Zhong, W., \& Zhang, Z.-X. (2019). Deploying human capital for innovation: A study of multi-country manufacturing firms. International Journal of Production Economics, 208, 241253.

Liu, C.-H. (2017). Creating competitive advantage: Linking perspectives of organization learning, innovation behavior and intellectual capital. International Journal of Hospitality Management, 66, 13-23.

Mariz-Perez, R., Teijeiro-Alvarez, M., \& Garcì-Alvarez, M. (2012). The relevance of human capital as a driver for innovation. Cuadernos de Economía, 35(98), 68-76.

Mthanti, T., \& Ojah, K. (2017). Entrepreneurial orientation (EO): Measurement and policy implications of entrepreneurship at the macroeconomic level. Research Policy, 46(4), 724739.

Pittino, D., Visintin, F., \& Lauto, G. (2017). A configurational analysis of the antecedents of entrepreneurial orientation. European Management Journal, 35(2), 224-237.

Prámartens, C. D., Machado, F. J., Martens, M. L., Silva, F., \& Freitas, H. (2018). Linking entrepreneurial orientation to project success. International Journal of Project Management, 36(2), 255-266.

Pratono, A. H., \& Mahmood, r. (2015). Entrepreneurial orientation and firm performance: How can micro, small and medium-sized enterprises survive environmental turbulence? Pacific Science Review B: Humanities and Social Sciences, 1(2), 85-91.

Pratono, A. H., Darmasetiawan, N. K., Yudiarso, A., \& Gyo, B. (2019). Achieving sustainable competitive advantage through green entrepreneurial orientation and market orientation: The role of inter-organizational learning. The Bottom Line, 32(1), 2-15.

Pratono, A. H., Ratih, R. V., \& Arshad, D. (2018). Does Entrepreneurial Autonomy Foster SME Growth Under Technological Turbulence? The Empirical Evidence from Indonesia. Journal of Technology in Behavioral Science, 3(3), 170-178.

Rahman, N., \& Ramli, A. (2014). Entrepreneurship Management, Competitive Advantage and Firm Performances in the Craft Industry: Concepts and Framework. Procedia-Social and Behavioral Sciences, 145, 129-137.

Rezaei, J., Ortt, R., \& Scholten, V. (2013). An improved fuzzy preference programming to evaluate entrepreneurship orientation. Applied Soft Computing, 13(5), 2749-2758. 
Rodrigo-Alarcón, J., García-Villaverde, P., Ruiz-Ortega, M., \& Parra-Requena, G. (2018). From social capital to entrepreneurial orientation: The mediating role of dynamic capabilities. European Management Journal, 36(2), 195-209.

Ruíz, M. A., Gutiérrez, J. O., Martínez-Caro, E., \& Cegarra-Navarro, J. G. (2017). Linking an unlearning context with firm performance through human capital. European Research on Management and Business Economics, 23, 16-22.

Thompson, M. (2018). Social capital, innovation and economic growth. Journal of Behavioral and Experimental Economics, 73, 46-52.

Vaznyte, E., \& Andries, P. (2019). Entrepreneurial orientation and start-ups' external financing. Journal of Business Venturing, 34(3), 439-458.

Wincent, J., Thorgren, S., \& Anokhin, S. (2014). Entrepreneurial orientation and network board diversity in network organizations. Journal of Business Venturing, 29(2), 327-344.

Zehir, C., Can, E., \& Karaboga, T. (2015). Linking Entrepreneurial Orientation to Firm Performance: The Role of Differentiation Strategy and Innovation Performance. Procedia-Social and Behavioral Sciences, 210, 358-367.

Zehir, C., Gurol, Y., Karaboga, T., \& Kole, M. (2016). Strategic Human Resource Management and Firm Performance: The Mediating Role of Entrepreneurial Orientation. Procedia - Social and Behavioral Sciences, 235, 372-381.

Zhang, S., Yang, D., Qiu, S., Bao, X., \& Li, J. (2018). Open innovation and firm performance: Evidence from the Chinese mechanical manufacturing industry. Journal of Engineering and Technology Management, 48, 76-86.

Zhao, H., Teng, H., \& Wu, Q. (2018). The effect of corporate culture on firm performance: Evidence from China. China Journal of Accounting Research, 11(1), 1-19. 